\title{
AS ABORDAGENS ACERCA DA HISTÓRIA IBÉRICA MEDIEVAL EM LIVROS DIDÁTICOS
}

\author{
The Approaches on Medieval Iberian History in \\ Didactic Books
}

Fabiana de Oliveira

Maria Aparecida Avelino ${ }^{2}$

\begin{abstract}
RESUMO
A presente reflexão é resultado de uma pesquisa qualitativa de cunho documental que visou estudar as abordagens da História Ibérica medieval em livros didáticos de História e sob essa perspectiva refletir sobre a diversidade cultural, étnica e religiosa. Dessa forma, pretende-se compatibilizar duas preocupações: trazer à luz a discussão do tema da diversidade em um período e espaço específicos, e investigar de que maneira esse tema está sendo abordado nas publicações didáticas. Buscou-se responder à seguinte questão de pesquisa: considerando a diversidade cultural, étnica e religiosa da Península Ibérica Medieval, quais
\end{abstract}

\footnotetext{
${ }^{1}$ Formada em Pedagogia pela Universidade Federal de São Carlos (UFSCar). Mestrado e Doutorado em Educação pela mesma instituição. Pós-Doutorado em Educação pela Faculdade de Filosofia, Ciências e Letras de Ribeirão Preto (FFCLRP/USP). É docente da Universidade Federal de Alfenas (UNIFAL-MG) e atua no Programa de Pós-Graduação em História Ibérica (PPGHI) dessa instituição.

${ }^{2}$ Possui graduação em História pelo Centro Universitário do Sul de Minas - Unis (1988), Especialização em Metodologia do Ensino pelo Centro Superior de Ensino e Pesquisa de Machado - CESEP (1994). Mestrado em História Ibérica pela Universidade Federal de Alfenas. Área de concestração: Ensino e Pesquisa de História Ibérica. Atualmente é Técnica em Assuntos Educacionais no Instituto Federal de Educação, Ciência e Tecnologia do Sul de Minas Gerais Campus Machado. Possui experiência significativa na Educação Básica como professora de História e como gestora.
} 
são as abordagens presentes nos livros didáticos de História, do $1^{\circ}$ ano do Ensino Médio, aprovados no Programa Nacional do Livro Didático (PNLD) para o Ensino Médio 2015-2017? Assim se mostra relevante saber como essas temáticas vem sendo abordadas na História Ibérica problematizando o livro didático como instrumento de apoio para a construção de propostas de ensino voltadas para essa área do conhecimento. Os resultados encontrados nos levam a afirmar que os livros analisados denotam uma expressiva abertura no que se referem às discussões historiográficas contemporâneas quando dispõem de um espaço significativo ao período medieval, buscando desconstruir mitos e estereótipos. Entretanto, no que se referem aos conteúdos sobre a Península Ibérica se notou uma abordagem simplificada e correlacionada com o processo histórico de outras regiões da Europa como: a França, a Inglaterra e a Alemanha. Especificamente, sobre a diversidade cultural e religiosa, fruto das relações entre cristãos, muçulmanos e judeus no medievo ibérico, a menção se deu de maneira pontual no contexto da expansão islâmica.

Palavras-chave: Idade Média; Península Ibérica; Livro Didático.

\begin{abstract}
The present reflection is the result of a qualitative documentary research that aimed to study the approaches of medieval Iberian History in textbooks of History and from this perspective to reflect on cultural, ethnic and religious diversity. Thus, it is intended to reconcile two concerns: bring to light the discussion of the theme of diversity in a specific period and space, and investigate how this theme is being approached in didactic publications. Considering the cultural, ethnic and religious diversity of the Medieval Iberian Peninsula, what are the approaches in the History textbooks, of the 1st year of High School, approved in the National Program of Didactic Book for the High School 2015-2017? Thus is relevant to know how these themes are discussed in Iberian History problematizing the textbook as support for teaching proposals focused on this area of knowledge. The results lead us to affirm that the analyzed books show an expressive openness in what refers to contemporary historiographical discussions when they have a significant space to the medieval period, seeking to deconstruct myths and stereotypes. However, as regards to the contents of the Iberian Peninsula, a simplified and correlated approach with the historical process of other Europe regions such as France, England and Germany was noted. Specifically, on the cultural and religious diversity, fruit of the relations between Christians, Muslims and Jews in the Iberian Medieval, the mention occurred in a punctual way in the context of the Islamic expansion.
\end{abstract}

Keywords: Middle Ages; Iberian Peninsula; Didactic Books. 


\section{Introdução}

Ao estudar as abordagens da História Ibérica medieval nos livros didáticos da Educação Básica e sob essa perspectiva refletir sobre a diversidade cultural, étnica e religiosa da Península Ibérica Medieval nos livros didáticos de História, pretende-se compatibilizar duas preocupações: trazer à luz a discussão do tema da diversidade em um período e espaço específicos, e investigar de que maneira esse tema está sendo abordado nas publicações didáticas.

Para o desenvolvimento da presente pesquisa foi estabelecida uma questão central que estruturou o estudo: considerando a diversidade cultural, étnica e religiosa da Península Ibérica Medieval, quais são as abordagens presentes nos livros didáticos de História, do $1^{\circ}$ ano do Ensino Médio, aprovados no Programa Nacional do Livro Didático para o Ensino Médio - PNLD/2015-2017?

Especificamente, pretende-se analisar como as publicações têm abordado o tema da diversidade cultural, étnica e religiosa do medievo ibérico e apresentar as imagens que os livros mostram sobre os muçulmanos e sobre os judeus. Diante disso, a discussão partiu dos seguintes pontos: por que a Idade Média na Península Ibérica continua sendo desconhecida pelos professores, pelos autores de livros didáticos e, consequentemente, pelos estudantes da escola básica? Que conteúdos são explicitados e/ou suprimidos nos manuais didáticos que possam apresentar as trocas culturais entre cristãos, muçulmanos e judeus? Torna-se relevante conhecer como esses agentes são inseridos na História Ibérica, problematizando o livro didático como instrumento de apoio para a construção de propostas de ensino de História Ibérica.

Os livros didáticos se prestam a conceder um protagonismo aos católicos (europeus ibéricos) em detrimento dos muçulmanos e judeus na Península Ibérica. Esse modelo é repetido na abordagem da colonização do Brasil, uma vez que, novamente, é negado o protagonismo aos não europeus, no caso, aos africanos e nativos (indígenas). Ou seja, os livros didáticos mantêm um eurocentrismo, apresentando uma visão com reminiscências cruzadísticas. A pouca presença e frequência dos conteúdos referentes à medievalidade ibérica são feitas com o intuito de operar uma separação: nós/outros, 
sendo que "nós" seriam os ibéricos (europeus) e os "outros" seriam os negros, indígenas, muçulmanos, judeus.

A Península Ibérica, ao longo da Idade Média, foi palco da convivência entre as três religiões monoteístas que ali coexistiram: cristãos, muçulmanos e judeus. De acordo com Macedo (2000), os mouros $^{3}$, incorporados ao domínio cristão, construíram juntamente com os judeus, as minorias étnico-religiosas de Portugal e da Espanha. A permanência dos mouros por tanto tempo na Península Ibérica deixou marcas profundas de sua cultura no imaginário europeu. E a América portuguesa não ficaria imune a essa influência. $\mathrm{O}$ mesmo ocorre com os judeus, com uma vida rica em religiosidade $\mathrm{e}$ cultura, contribuíram para o fortalecimento do grupo e para a continuidade de suas tradições, transplantando toda essa herança para o Novo Mundo.

Quando se trata de História do Brasil, por exemplo, a tendência é iniciar a abordagem a partir da chegada dos portugueses ao território brasileiro. No entanto, refletir sobre a história, instituições, comportamentos e sentimentos transferidos do continente europeu para as novas terras constitui-se um exercício importante. De acordo com Franco Júnior (2008), muitos elementos medievais foram transportados de Portugal para a colônia brasileira, permanecendo presentes ainda hoje em nossos traços essenciais.

Revisitar o tema da formação dos povos ibéricos tem se tornado estratégia importante na busca da compreensão das características herdadas e de suas influências na forma de ver e de pensar a cultura brasileira. O período medieval está presente nas estruturas mais básicas e essenciais da sociedade da América portuguesa. Franco Júnior (2008, p.82) enfatiza que: "Mais do que na civilização portuguesa moderna, as raízes do Brasil deverão se

3 "O termo mouro, utilizado em um sentido amplo para definir os invasores muçulmanos da península Ibérica, refere-se [...] a povos de várias origens, mas, sobretudo, aos habitantes islâmicos do norte da África". (ALVES, 2010, p. 14). Outro exemplo é apresentado por Alves (2010) que cita a pesquisadora Ana Rita Gaspar Moreira que, após várias elaborações em torno do termo mouro, concluiu: "Mouros são afinal, com alguma consistência, as populações muçulmanas: os dominadores árabes, os berberes islamizados, os muçulmanos que se conservam na península depois da conquista cristã ou os que os navegadores vão reencontrar, a partir do século XV, nas suas expedições em África e Ásia" (MOREIRA, 2005, p. 79 apud ALVES, 2010, p 15). 
procurar, portanto, na Europa medieval", sobretudo em sua influência mais profunda.

Acredita-se, então, ser necessária uma discussão do espaço da Península Ibérica no Ensino de História do Brasil, uma vez que Portugal e Espanha tiveram relevantes contribuições na História da América Latina. Assim, crenças, valores, ética e religiosidade têm suas raízes na Península Ibérica Medieval. Estudar sobre a diversidade cultural, étnica e religiosa desse período poderá trazer uma contribuição importante para a compreensão da formação cultural do Brasil. Nessa perspectiva, considerou-se importante problematizar o livro didático com a finalidade de se analisar como a História da Península Ibérica Medieval foi abordada em seu conteúdo.

\section{Aspectos metodológicos da pesquisa}

Para o estudo do problema apresentado neste trabalho foi realizada uma pesquisa documental. De acordo com Godoy (1995), a análise de documentos se constitui numa valiosa técnica de abordagem de dados qualitativos e de complementação de informações obtidas através de outras fontes.

Foram selecionados como documentos livros didáticos de História do $1^{\circ}$ ano do Ensino Médio adotados em duas escolas estaduais e em uma da rede federal de dois munícipios do Sul de Minas Gerais. Os livros fazem parte da coleção aprovada e ofertada pelo PNLD para o triênio 2015/2017. Assim, foram analisados dois livros, uma vez que as duas escolas estaduais, a escola A e a escola B adotam o mesmo livro; a escola $\mathrm{C}$, uma instituição federal outro manual.

A análise se concentrou nos capítulos que fazem referência ao tema desta pesquisa que é a diversidade cultural, étnica e religiosa do medievo ibérico, embora os títulos sejam diversos. Buscou-se, dessa forma, a verificação das imagens e dos textos que esses livros trazem sobre a convivência entre cristãos, muçulmanos e judeus, nesse período e contexto geográfico específico para a compreensão de como o assunto é abordado.

A discussão do conteúdo que é abordado no manual didático pressupõe compreender como o currículo, importante instrumento que 
serve de guia ao processo ensino-aprendizagem, é construído. A complexidade das dimensões do currículo exige uma posição quanto aos conteúdos que serão selecionados para que os objetivos sejam alcançados. Esses conteúdos devem estar de acordo com o público alvo e, além disso, é preciso considerar também os métodos e os processos formativos do sujeito. Fonseca (2010, p. 2) afirma que: “a história ensinada é sempre fruto de uma seleção, ou como atualmente se diz, de um 'recorte temporal', histórico. As histórias são frutos de múltiplas leituras, interpretações de sujeitos históricos situados socialmente".

Um dos espaços onde se constitui parte desse processo é o livro didático. Problematizá-lo significa pensar no currículo, entender como ele é construído e as implicações das orientações oficiais que o norteia. Ainda, entender que no ambiente escolar esse currículo é ressignificado por sofrer interferências das relações sociais que se estabelecem em seu interior e também das relações de poder que inevitavelmente acabam por sobrepor um grupo ao outro.

$\mathrm{Na}$ perspectiva de Choppin, entre as funções que são exercidas pelo livro didático há a Função Curricular que reputa ao manual a responsabilidade pela fidelidade ao programa e quando há concorrência de uma de suas interpretações. O livro escolar "constitui o suporte privilegiado dos conteúdos educativos, o depositário dos conhecimentos, técnicas ou habilidades que um grupo social acredita que seja necessário transmitir às novas gerações" (CHOPPIN, 2004, p. 553).

No que concerne às pesquisas realizadas acerca do livro didático, são identificadas duas linhas: uma que trata das pesquisas que concebem o manual escolar somente como um documento histórico e analisam seus conteúdos, como o estudo de um determinado tema, na busca de informações estranhas a ele e a outra que o analisa enquanto objeto físico e produto que foi fabricado, comercializado, distribuído, consumido e avaliado em certo contexto (CHOPPIN, 2004).

A análise que se seguirá, a partir do aporte de Choppin (2004), fundamenta-se nessa primeira linha e buscará discorrer sobre a abordagem do tema da Península Ibérica Medieval no livro didático, que é apenas uma das fontes a que a pesquisa recorrerá. $\mathrm{O}$ autor reitera que o diferencial entre essas duas proposições é esquemática, 
uma vez que, uma pesquisa participa - ainda que em proporções variáveis - das duas categorias.

O que as análises apontam sobre as abordagens presentes nos livros didáticos de História, do $1^{\circ}$ ano do Ensino Médio, aprovados no Programa Nacional do Livro Didático para o Ensino Médio PNLD/2015-2017?

Nos últimos tempos, a Idade Média tem sido "inventada e reinventada, sendo esse processo observado desde meados do século passado paralelamente ao movimento de produção da chamada Nova História" (OLIVEIRA, 2010, p.106). É dessa forma que a historiografia medievalista tem procurado mostrar esse período. Partindo das diversas definições, problematiza com o intuito de provocar a reflexão do aluno, a partir da compreensão mais abrangente do período e de todos os acontecimentos que nele tiveram espaço.

E nessa perspectiva de pensar o espaço e, nesse caso, situar a Península Ibérica Medieval no contexto histórico da Europa Ocidental, no livro didático 1 , logo na abertura da unidade 6 , notou-se que é reproduzida uma série de abordagens tradicionais sobre o medievo em geral, diluindo ou silenciando referências específicas sobre a Península Ibérica. A introdução traz a seguinte epígrafe: "Idade Média, com o cristianismo, a Igreja, o feudalismo, a formação dos Estados-nações, a vida intelectual dirigida por escolas e universidades (...) foi o longo caminho de formação da Europa". Verifica-se que há uma relação estreita entre período medieval e Europa ocidental, estando o Império Carolíngio no centro da discussão. A esse respeito Lima (2012, p. 168) argumenta que:

Apesar das mudanças dos últimos anos, é ainda essa relativa marginalidade de referências à Península Ibérica Medieval que tem predominado no conjunto da produção de conhecimentos históricos veiculados pelo ensino de História. Como parte desse processo, os livros didáticos também são influenciados por uma dupla limitação, ora representando a Península Ibérica como uma região deslocada e ignorada, ora sendo englobada e interpretada à luz de outras regiões 
consideradas um padrão modelar e recorrente de Idade Média.

Embora o livro didático 1 ofereça elementos para a compreensão da formação da Europa ocidental, partindo das migrações germânicas e da desagregação do Império Romano do Ocidente, ao tratar da vida social, política, econômica e cultural dos séculos $\mathrm{V}$ ao $\mathrm{XV}$, o capítulo faz uma breve abordagem sobre as invasões ocorridas nos séculos IX e X. Nesse contexto é aludida a penetração muçulmana no território da Península Ibérica, porém na perspectiva de explicar o isolamento europeu, a proliferação dos castelos fortificados e a formação do sistema feudal.

No sul, houve a penetração dos muçulmanos (ou sarracenos), que conquistaram parte da península Ibérica e empreenderam sucessivos ataques de pilhagem à península Itálica. Com a insegurança provocada pelas invasões, os europeus ocidentais procuraram se proteger, buscando refúgio no campo (Livro 1, 2013, p. 182).

De acordo com Macedo (2007), os livros didáticos conferem aos conceitos como o feudalismo, a sociedade feudal ou o sistema feudal, uma lógica ao desenvolvimento histórico de toda a Europa, como se houvesse um mesmo "feudalismo" ou uma mesma "sociedade feudal" nos quatro cantos do continente. Para o autor, é preciso descolonizar o ensino de História, significando isso o reconhecimento de identidades como Portugal e Espanha que, em geral, são mantidas em segundo plano.

O caminho seria, a partir dos países ibéricos, realizar um trabalho em conjunto com os conhecimentos prévios dos alunos, adquiridos ao longo do Ensino Fundamental, questionando a eurocentricidade e as consequências que a colonização trouxe ao território brasileiro. Desse modo, encontra-se, também, uma contextualização maior entre a Idade Média e o Brasil.

No livro didático 2, o próprio termo Idade Média é criticado. No entanto, não há uma menção aprofundada à forma como esse conceito foi construído, nem mesmo uma explicação referente ao significado de um período intermediário e de que se aplica apenas à Europa. O trecho abaixo, quando cita as instituições e sistemas 
culturais que se formaram no período, como as universidades e os bancos e se refere às Igrejas Católica e Ortodoxa e ao Islã, amplia a discussão. Mas, a menção ainda se limita à Europa Ocidental. Para contextualizar essa abordagem, o professor poderá disponibilizar, na sala de aula, a discussão em torno das relações dessa parte da Europa com a Ásia e com a África, culturas que nessa época se encontravam em pleno florescimento.

No período medieval formaram-se instituições e sistemas culturais importantes, como as universidades, os bancos, as igrejas (católica e ortodoxa) e o Islã. Mas como esses valores, instituições e personagens interagiram? Como saber que heranças a Antiguidade passou para o período medieval e o que esse período legou à chamada Idade Moderna? (Livro 2 , 2013, p. 105).

Nessa mesma linha, pôde-se observar no livro didático 1, que a unidade se limitou à Europa Ocidental para apresentar os aspectos gerais sobre a Idade Média. A proposta para o professor, ao trabalhar com esse manual, é também explicitar o que acontecia em outras regiões da Europa e do Mundo nesse período, a fim de que os alunos possam interpretar e avaliar criticamente o conceito. Pois, mesmo com os esforços de professores, pesquisadores e autores, a Idade Média ainda permanece viva no imaginário da maioria das pessoas como um período marcado por hábitos violentos e pela inexistência de uma produção cultural.

A forma abreviada com que o tema foi tratado nesses manuais remete à seguinte reflexão: por que a Idade Média, pensada e repensada pelos pesquisadores, ainda é pouco discutida no livro didático? Por que a versão estereotipada dos renascentistas e dos iluministas ainda é mais conhecida e difundida do que as visões que são apresentadas pelos estudos mais recentes? Observar essas questões pode trazer a possibilidade de percepção das eventuais lacunas no processo ensino-aprendizagem desse campo do conhecimento, bem como apontar caminhos a serem seguidos.

Essa questão é debatida por Macedo (2007, p. 112) ao afirmar que: 
A Idade Média ensinada na escola, todavia, não é a Idade Média dos pesquisadores. Nesse caso, a função social da História tem estatuto diferente do conhecimento erudito e acadêmico, continuando a estar ligado à constituição da memória da nação, do Estado moderno e da supremacia ocidental no mundo.

No capítulo 6 do livro didático 2, cujo título é $A$ constituição do mundo feudal, verifica-se que a preocupação central é apresentar as bases do sistema político, econômico e social da Idade Média: o Feudalismo. E, como o objetivo desta pesquisa é buscar no conteúdo desse manual as abordagens sobre a Península Ibérica, constatou-se que o tema é tratado superficialmente.

Nota-se que é uma afirmativa que dá margem para interpretações estereotipadas, ao vincular os muçulmanos à destruição da doutrina cristã. O que é passível de questionamento, uma vez que, segundo Pedrero-Sanches (2005), Macedo (2004) e Castro (2012), o clima era de tolerância e de convivência na Península Ibérica, ao longo da Idade Média. Segundo esses autores, a tolerância se baseava na relação com os "Povos do Livro", que possibilitou tanto a judeus quanto a cristãos conservar, após a ocupação, uma série de direitos pessoais e religiosos, embora essa permissão se condicionasse ao pagamento de tributos e à submissão à autoridade muçulmana.

Outras referências sobre a Península Ibérica e sobre os muçulmanos são encontradas, porém, notadamente, de forma muito simplificada e na perspectiva de elucidar os fatos considerados mais relevantes do período, como o Império Franco-Carolíngio, as Cruzadas e a cristandade europeia. O que explica a pouca menção ao que ocorria em Portugal e na Espanha no período de dominação islâmica? Silenciar certos conteúdos pode resultar em preconceitos. No caso da Idade Média europeia, por exemplo, uma das religiosidades que mais sofrem equívocos nos livros didáticos é o Islamismo, podendo esse fato contribuir para a formação de preconceitos nos alunos (CAMPOS; LANGER, 2007).

A unidade que tem como título $O$ Islamismo, no livro didático 1 é aberta com uma epígrafe de Peter Demant: "É notável a semelhança das duas revoluções monoteístas anteriores, o judaísmo e o cristianismo, com a crença e o ritual básico do Islã que, aliás, se 
considera a continuação e o aperfeiçoamento daquelas". [...] (2013, p. 138), que introduz o assunto fazendo menção ao islamismo como um aperfeiçoamento das outras duas religiões monoteístas: o cristianismo e o judaísmo.

O professor poderá aprofundar a análise dessa introdução e do texto como um todo, a fim de investigar, juntamente com os alunos, a História da Península Ibérica a partir do ano de 711, quando $\mathrm{Al} \mathrm{Andalus}^{4}$ foi ocupada pelos muçulmanos. Ainda, aprimorando sobre os acontecimentos que sucederam no interior da região, buscando entender como se deu o encontro entre as três religiões monoteístas. E aproveitando esse contexto, elaborar discussões sobre conceitos como: tolerância, preconceito, diversidade, cooperação, respeito, desprezo, alianças e guerras.

O capítulo 12 dessa unidade, intitulado Mundo islâmico, trata o islamismo se referindo à cultura árabe no Oriente Médio, norte da África e na Península Ibérica. Relata a origem da religião islâmica e sobre a importância de Maomé, dando ênfase aos princípios básicos do islamismo. O surgimento do Islamismo e a desagregação do Império muçulmano são sempre relacionados ao cristianismo.

No livro didático 2, O mundo islâmico é o título do capítulo 8 , cujo conteúdo apresenta o contexto histórico social presente na formação do islamismo. A abordagem tem início com um breve relato sobre Maomé e sobre o momento que marca o surgimento da nova crença monoteísta. Segue apresentando as principais características do Islã, como a crença em um deus único e a submissão do ser humano a Alá.

A expansão árabe e a formação do império islâmico são abordadas no livro didático 1 , sem, contudo, um aprofundamento das razões políticas, econômicas, religiosas, militares e culturais da expansão territorial. Também, se houve resistência ou aceitação por parte da população das regiões conquistadas. Quanto à constituição de Al-Andalus, o autor não trata, especificamente, a respeito da ocupação muçulmana no ano de 711, na Península Ibérica e dos eventos, como

\footnotetext{
4 Nome dado aos territórios de matriz cultural e política arábico-islâmica na península Ibérica medieval.
} 
a crise do reino visigodo que, somados a outros fatores, desencadearam o processo de dominação muçulmana.

As ausências ou superficialidades de determinados conteúdos também podem ser problematizadas pelo professor. Observa-se que, diferentemente do livro didático 2, o livro 1 não aborda as causas e as consequências da dominação muçulmana. Por exemplo, uma das consequências foram as interações socioculturais que se estabeleceram na Península. A discussão em torno da formação de um local híbrido pode trazer ao aluno a capacidade de percepção da diversidade dos grupos, com suas distintas religiões, culturas e formações sociais.

$\mathrm{O}$ entendimento da diversidade cultural como princípio educativo estimula a aprendizagem de valores sociais e culturais do outro, desafiando os atores envolvidos na prática pedagógica, por meio do diálogo, a repensar as relações étnico-raciais, sociais, econômicas, políticas e culturais na sociedade, de maneira sensível, investigativa e responsável.

O livro didático 2 aponta que, uma das razões que explica o avanço da expansão islâmica, por vastas regiões, é o seu caráter integrador que pode ser entendido também como tolerância à diversidade cultural. Especificamente, em relação à Península Ibérica, o texto abaixo demonstra que a tolerância cultural e também a religiosa foram características que contribuíram para a formação de uma convivência pacífica entre as religiões monoteístas.

O domínio muçulmano na Espanha foi marcado pela tolerância religiosa. Judeus e cristãos podiam continuar professando sua fé e ser julgados conforme suas tradições, desde que pagassem um imposto. [...] Contraditoriamente, apesar das guerras entre cristãos e muçulmanos, houve uma grande interação cultural e comercial entre esses povos, a despeito das diferenças entre suas crenças religiosas (Livro 2, , 2013, p. 148).

Destaca-se a importância do texto-base quando discute a tolerância e a convivência harmônica entre as religiões monoteístas, embora não apresente uma análise mais aprofundada sobre as relações sociais que se estabeleciam entre os mais diversos grupos étnicos que compunham aquela sociedade. $\mathrm{O}$ trecho que será mostrado a seguir 
oferece condições para um debate em sala de aula a respeito desses valores, fazendo um paralelo com outros espaços e outros períodos. Além disso, poderá proporcionar ao aprendente a capacidade de analisar, de forma crítica, a visão da historiografia tradicional, ligada apenas à história da Europa cristã. - $\mathrm{O}$ ambiente de tolerância e livre reflexão que os califados e emirados propiciavam aos estudiosos era o oposto do que reinava na Europa medieval católica, e que reina hoje em todas as vertentes fundamentalistas de vários grupos religiosos\| (Livro 2, 2013, p. 150).

No livro didático 1, no capítulo Mundo Islâmico, também aborda a tolerância dos islâmicos em relação aos judeus e cristãos que puderam manter suas crenças. Assuntos relacionados à tolerância religiosa são essencialmente importantes para que os alunos tenham contato com o islamismo e o judaísmo, pois, em geral, as informações sobre esses temas são escassas e, muitas vezes equivocadas. $\mathrm{O}$ professor pode conduzir um debate sobre o que ocorreu na Península Ibérica Medieval, mencionando as relações entre as três religiões monoteístas. Também estabelecer uma relação com o presente, mostrando a situação dos judeus e muçulmanos fora do mundo árabe, inclusive no Brasil.

No que se concerne à relação passado e presente, seria oportuno trazer as informações da participação dos judeus que, além de constituírem um número significativo, contribuíram eficazmente com os governos muçulmanos e cristãos pela capacidade intelectual e conhecimento nas áreas administrativas e financeiras (PEDREROSANCHEZ, 2005).

Ao contrário dos cristãos, os judeus adotaram rapidamente a língua árabe e se integraram ao mundo islâmico. As capitais das regiões foram escolhidas por eles, que criaram comunidades florescentes em Córdoba, Toledo, Mérida, Sevilha, Saragoça, Granada e Lucena. Os membros de maior prestígio dessas comunidades ocuparam altos cargos nos palácios dos emires e dos califas, especialmente como médicos, tradutores e embaixadores (RUCQUOI, 1995).

A discussão a respeito dos judeus remete à análise de Feldman (2012). Para ele, refletir sobre o aporte cultural judaico no Ocidente e analisar as difíceis relações entre cristãos e judeus através dos séculos, pode contribuir para a compreensão do preconceito e 
ajudar na educação voltada para a diversidade religiosa, cultural e étnica. A problematização partiria do contexto que segregou e excluiu os judeus dos processos políticos e das instituições dominantes, controladas pelas autoridades cristãs e pela Igreja cristã medieval. A maior parte dos estereótipos antijudaicos foi construída no processo de expansão do Cristianismo. Perspectiva diferente da ocorrida na Península Ibérica sob o domínio muçulmano onde:

\begin{abstract}
Os judeus optam por viver sob o emirado e sob o califado de Córdoba e se beneficiam desta tolerância islâmica e do estatuto de Dhimmis. O período é testemunha de uma vitalidade cultural e espiritual do Judaísmo peninsular, que consolida a condição de centro cultural desta religião tradicional. A expressão Sefarad que significaria Espanha, mas que pode ser entendida como a Espanha judaica no contexto medieval ibérico é definida tanto como espaço, quanto como tempo de uma criação religiosa e cultural sem paralelos na Diáspora (FELDMAN, 2010, p. 4).
\end{abstract}

Outra questão que pode ser conduzida ao debate com os alunos é sobre o que alguns historiadores chamam de singularidade, tendo sido vivenciada no medievo ibérico em razão da coexistência de cristãos, muçulmanos e judeus. Mencionada também por Pedrero Sanches $(2005$, p. 5), quando afirma que as relações entre esses povos "foi uma situação única, não vivida em nenhum outro lugar. Nos oito séculos que ela durou, múltiplas influências e intercâmbios se processaram nos muitos momentos de paz estabelecidos em meio às guerras". Nessa mesma perspectiva, pode-se aludir Rucquoi (1995), ao afirmar que as três grandes comunidades religiosas e linguísticas criaram uma obra filosófica, artística, literária e científica de que a Europa setentrional dos séculos XII e XIII iria beneficiar e transformaram Al-Andalus numa terra de exceção, tanto no mundo islâmico como no mundo cristão.

No capítulo 7 do livro didático 2, A vida cultural da Europa medieval, o texto base apresenta, como centro da discussão, a importância da Igreja Católica e do cristianismo na formação de valores que orientaram a sociedade medieval. A abordagem trata da produção escrita nos mosteiros e catedrais que teriam preservado os textos gregos e romanos, enfatizando a importância dessas 
instituições para o cristianismo. Da mesma forma, o capítulo 16 do livro didático 1 cujo tema é a cultura medieval, também enfatiza a discussão em torno da influência da Igreja Católica nas diversas manifestações culturais.

A atividade intelectual em ambos os manuais é retratada ao citar o surgimento das universidades, a escolástica, a arquitetura religiosa e os aspectos da cultura popular; contudo, o papel da Península Ibérica nesse processo é ignorado. Em relação aos filósofos que se destacaram nesse período, são elencados autores como Agostinho e Tomás de Aquino para a discussão da temática das relações entre fé e razão.

Nota-se a ausência de Averróis e Maimônidas, cujos trabalhos foram fundamentais para o surgimento de uma consciência andaluza. "O grande movimento intelectual e filosófico de AlAndalus, data dos séculos X e XI, tendo Averróis e Maimônidas constituído no século XII seu último florão" (RUCQUOI, 1995, p. 68). No livro didático 1 se encontra referência às obras que foram traduzidas do árabe e do grego, inclusive menciona os avanços na navegação por meio da utilização da bússola, de mapas, do astrolábio etc. O docente pode aproveitar para elaborar uma proposta de pesquisa sobre a origem desses instrumentos e a importância dessas inovações para os países ibéricos.

Quando se referem às universidades, são citadas as cidades onde foram construídas. O livro didático 1 traz um mapa e uma proposta de atividade para que o aluno identifique em que países da Europa atual se localizavam os centros intelectuais da Idade Média como a de Bolonha (1088), a de Oxford (1096), a de Paris (1170), a de Salamanca (1218) etc. Ressalta-se que nesse livro didático não se estabelece uma cronologia sobre a fundação das universidades, ao contrário do livro didático 2. Essa e outras questões também podem ser elencadas com a finalidade de fornecer esclarecimentos sobre em que contexto ocorreu suas construções e o papel dessas universidades para o mundo medieval.

O esplendor cultural experimentado pela Península Ibérica, como resultado das trocas culturais entre cristãos, muçulmanos e judeus, não foi discutido pelos manuais nesses capítulos que tratam da cultura. O florescimento dessa convivência poderia contribuir para um debate sobre a diversidade, uma vez que, 
as trocas culturais foram tão intensas (entre iberos, romanos, visigodos, judeus, muçulmanos, africanos, muçulmanos ibéricos, moçárabes, mudéjares e cristãos de outras partes) que a categorização e a identificação de elementos culturais próprios de uma determinada cultura dificilmente podem ser absolutas (SILVEIRA, 2013, p. 137).

Como mencionado anteriormente, ao apresentar as contribuições no campo da Filosofia, não houve menção a Avicena e Averróis. Averróis, que se destacou por tornar a obra de Aristóteles conhecida, é citado somente no livro didático 2, no capítulo denominado "O Mundo Islâmico".

Os dois livros didáticos afirmam que muitos eruditos viajavam para a Europa muçulmana com a pretensão de entrar em contato com os pensadores árabes. Sendo assim, usar a parte do texto que evidencia a importância dos trabalhos filosóficos e científicos desses autores e abordar a influência de Maimônides, Yeudah ben Levi (judeus), Avicena, Averróis e Alfarabi (árabes), poderá auxiliar o professor para, juntamente com os alunos, aprofundar na identificação das principais contribuições das filosofias orientais (árabe e judaica) para a construção de grandes doutrinas do período medieval.

A intensa atividade artística e intelectual do medievo ibérico e o seu legado foram temas de discussão nos dois livros didáticos que possuem um capítulo sobre o Islamismo, porém os aspectos apresentados nos dois livros poderiam ter sidos abordados de forma mais abrangente, demonstrando que esse florescimento cultural resultou das trocas culturais e do diálogo inter-religioso que se processou no território ibérico de dominação muçulmana. Segundo Macedo (2007), a convivência entre os adeptos das três grandes religiões monoteístas revela uma particularidade ibérica que nada ficou devendo a outros povos e complementa:

Sem essa convivência não teria havido trocas culturais tão profícuas, cujo melhor exemplo no caminho intelectual é a conhecida Escola de Tradutores de Toledo, em boa parte responsável pela difusão do conhecimento grego no Ocidente por meio de obras árabes convertidas ao latim por tradutores judeus (MACEDO, 2007, p. 117). 
O livro didáticol aborda, de modo sistematizado, as contribuições dos muçulmanos na produção agrícola, como a construção de grandes obras de irrigação que tornaram produtivas terras antes consideradas estéreis. Ao mesmo tempo, aponta a expansão da atividade comercial nas diversas regiões do mundo e exalta bastante a habilidade comercial e artesanal desses povos.

No que se refere à cultura, esse livro didático enfatiza sobre a propagação de descobertas e conhecimentos como: a bússola, a pólvora e o papel; de textos da Antiguidade Clássica; e do idioma árabe. As contribuições árabes na ciência como a Matemática, a Medicina e a Química também são abordadas. O autor discorre ainda sobre o impacto árabe na cultura ibérica, atribuindo um destaque à arquitetura, mencionando ainda a música, a comida e as roupas. Achando pertinente, o professor poderá fazer uma introdução para demonstrar que os avanços científicos e culturais estão relacionados às relações entre cristãos, muçulmanos e judeus em Al-Andalus, entre os séculos VIII a XV.

Nessa linha, o trabalho de Silveira $(2009$, p. 405) reitera que:

Séculos antes da obra de Aristóteles ser discutida na Paris do século XIII, muçulmanos, cristãos e judeus já trabalhavam em conjunto na tradução e interpretação de textos aristotélicos na escola de tradução de Bagdá (séculos VII-IX d. C.). A mesma colaboração é documentada na escola de tradução de Toledo (século XII-XIII), a qual traduziu os trabalhos do árabe para o latim.

As traduções da obra de Aristóteles denotam a intensidade da troca cultural entre cristãos, judeus e muçulmanos, na Idade Média, e esse tipo de intercâmbio pode ser considerado um exemplo da importância das culturas mediterrânicas na formação cultural da Europa, cuja tendência sempre foi a disseminação da Idade Média, a partir da civilização carolíngia.

Podemos concluir que a partir das análises realizadas que os equívocos, as lacunas e os destaques a determinados temas podem resultar em preconceitos. O estudioso Edward W. Said, em sua obra Orientalismo, que retrata a visão do mundo oriental pelo ocidental, adverte que a proposição através da qual se divide o mundo em 
oriente e ocidente, embora resguardada sob o inocente propósito de simples diferenciação, serve, na realidade, para intensificar as discriminações e impossibilitar quaisquer tentativas de aproximação entre as culturas.

Para Said (1990), a visão do europeu em relação ao Oriente é puramente racista, e a saída para a desconstrução da subjugação oriental seria o desenvolvimento de estudos despidos dos velhos preconceitos. Acrescenta: "Investigar o orientalismo é também propor modos intelectuais de tratar os problemas metodológicos a que a história deu origem, por assim dizer, em seu tema de estudos, o Oriente" (SAID, 1990, p. 119).

\section{Considerações Finais}

Esta investigação buscou analisar as abordagens da História Ibérica Medieval no livro didático. Um dos primeiros aspectos que foram percebidos através desta pesquisa é que os dois livros didáticos expressaram os acontecimentos históricos na perspectiva da periodização tradicional. A importância da divisão da História em períodos consiste na necessidade de sistematização do conhecimento. Portanto, o uso didático desse recurso é inerente ao processo de produção do conhecimento histórico, como acentua Le Goff:

A periodização é uma racionalização, oferece vantagens
como permitir uma abordagem "científica" do conhecimento
do passado e especialmente do passado em relação ao
presente, porque o período ocupa um lugar na cadeia
temporal. Mas também apresentam riscos, em particular os da
simplificação e do achatamento da realidade histórica. [...] só
é um bom instrumento para o historiador se houver condição
para seu método científico seja o de uma ciência que não
tenha a rigidez das ciências naturais (LE GOFF, 2008, p. 12).

Ambos os livros didáticos organizam predominantemente os conteúdos históricos de maneira cronológica e se propõem a apresentar uma perspectiva integrada dos conteúdos da História Geral e do Brasil. Apesar disso, são marcados pelo viés eurocêntrico, com 
abordagens separadas das histórias africana, americana e asiática, como fica evidenciado pela organização dos capítulos e unidades.

É nesse contexto que a relevância da abordagem do tema da Península Ibérica Medieval, nos conteúdos desses manuais, foi analisada. Foi constatado o privilégio da Europa em relação às demais regiões que somente passam a existir a partir do contato com esse continente. A menção ao medievo ibérico se desenvolveu numa perspectiva linear e teleológica para explicar os eventos históricos ocorridos em outras partes da Europa, como a França, a Inglaterra e a Alemanha. A visão etnocêntrica também é percebida quando há uma concessão de um protagonismo aos católicos em detrimento dos muçulmanos e judeus.

A escassa presença e frequência dos conteúdos referentes à medievalidade ibérica tem relação com a historiografia, com forte tendência francesa do movimento dos Annales que viam os medievalistas como Marc Bloch, Jacques Le Goff e George Duby como referências inovadoras e obrigatórias. No entanto, seus trabalhos se concentraram em outras regiões da Europa, excetuando a Península Ibérica (LIMA, 2012).

Outra questão que impacta na dinâmica da produção dos livros didáticos são os descompassos entre o que se produz na academia e o que chega até os manuais. A historiografia tem produzido saberes sobre a Península Ibérica Medieval (LIMA, 2012). Todavia, nas duas publicações analisadas, os autores definem a Península Ibérica Medieval como sendo uma região deslocada, periférica, abordando esse contexto histórico como pano de fundo para outra região considerada o centro do continente europeu.

Há, ainda, outros entraves que interferem na produção final dos conteúdos dos manuais como, por exemplo, o acesso às fontes ainda não publicadas e digitalizadas. Segundo Silva (2012), para os pesquisadores da Idade Média Ibérica, há pouco material disponibilizado online, dependendo da importação de obras, o que não ocorre com frequência, devido ao alto custo, ou das viagens desses pesquisadores, que também dependem de financiamento.

Como já mencionado, nenhuma das obras dedicou um capítulo específico ao medievo ibérico. Isto é uma lacuna, visto que é uma região bastante diferente do modelo francês que foi salientado para expor o período. No entanto, é importante ressaltar que se 
constatou um esforço, embora limitado, para ampliar a discussão em torno de conceitos como Idade Média, cultura, cotidiano, relações sociais, dentre outros.

No livro didático 1, foram assinaladas algumas generalizações ao associar o conceito de Idade Média ao Feudalismo. Nesse caso, ocorreu que o Império Bizantino e o Islã foram apresentados desmembrados do período medieval. Organização diferente do que foi constatada no livro didático 2, cuja distribuição dos conteúdos apresenta o Islã no contexto da Idade Média e reconhece que o feudalismo é apenas uma etapa da História da sociedade medieval.

Em ambas as publicações, os capítulos que tratam da cultura abriram um espaço para as diversas manifestações culturais do medievo ibérico salientando a presença das universidades, da literatura trovadoresca e das cavalhadas.

Segundo Silveira (2009), os oitocentos anos da presença muçulmana na Península Ibérica repercutiram na formação cultural da Europa; e a historiografia alemã e ibérica abrem o debate que tem como tema central uma Europa formada por valores ocidentais e orientais. Essa corrente apresenta "uma Idade Média que não é dividida em oriental e ocidental, mas definida pelos encontros e pelas trocas culturais, pelo trabalho conjunto nas traduções e pela identificação do outro como o nosso" (SILVEIRA, 2009, p. 408).

De maneira geral, a Península Ibérica não foi destacada, não sendo encontrada uma seção sequer dedicada ao tema. Quando se tratou da Idade Média, não foram apresentados elementos sobre o feudalismo especificamente na península e quando se tratou de $\mathrm{Al}$ Andalus, sua menção se deu no contexto da expansão islâmica, sem estabelecer uma relação com o que sucedia no restante da Europa. Elementos encontrados nos dois livros didáticos revelaram manifestações culturais da Península Ibérica, fruto das trocas entre cristãos, muçulmanos e judeus, que, com certeza, contribuirão para que os aprendentes compreendam a Idade Média como uma era que produziu cultura.

$\mathrm{Na}$ abordagem sobre as relações sociais e culturais entre os cristãos, muçulmanos e judeus em Al-Andalus, alguns avanços foram percebidos através da problematização de questões sobre pluralismo religioso e questões étnicas a partir de uma perspectiva crítica, de 
questionamentos e das possibilidades de diálogo. No entanto, ainda sem um aprofundamento dessas relações que, para alguns historiadores, fizeram de Al-Andalus uma sociedade singular. Esse contexto serviria para discutir uma visão de mundo que considerasse igualmente a diversidade cultural e étnica dos diversos grupos e ainda para aperfeiçoar valores como tolerância, preconceito e estereótipos. Isso, levando-se em consideração que o ensino é vinculado à formação de uma maneira determinada de enxergar o mundo, de ver a realidade e de formar conceitos para influenciar o mundo.

Foi possível observar também que a atual historiografia vem se firmando com novas expectativas em torno do pensar histórico. Sujeitos, antes esquecidos pela História, vêm cada vez mais adquirindo visibilidade na construção dessa nova História. Os costumes, as culturas e o cotidiano das pessoas tem ocupado cada vez mais espaço nas produções acadêmicas e no livro didático. $\mathrm{E}$ isso, embora de forma um pouco ainda tímida, está presente no conteúdo veiculado pelas imagens, textos e atividades das coleções investigadas.

Contudo, vale ressaltar que o manual escolar é apenas um dos elementos que integram o processo educacional e que, para que todas as expectativas de uma nova formação fundamentada na busca da compreensão da diversidade humana sejam atendidas, faz-se necessária a ressignificação do sistema educacional como um todo. Isso significa a reorganização dos objetivos, dos conteúdos, das metodologias e recursos, da relação professor-aluno, da avaliação e do espaço-tempo escolar.

\section{Referências Bibliográficas}

CAMPOS, L. ; LANGER, J. A História antiga e medieval nos livros didáticos: Uma avaliação geral. História e História, Campinas, 29 jun. $2007 . \quad$ Disponível em: $<\mathrm{http} / / / \mathrm{www}$.historiaehistoria.com.br/materia.cfm?tb=newsletter\&ID $=78>$. Acesso em: 23 set. 2015.

CASTRO, A. C. M. de. Sobre identidade e trocas culturais na "Espanha" medieval. Rev. Plêthos, v. 2, n. 1, p. 27-37, Niteroi, 2012. 
Disponível em: <www.historia.uff.br/revistaplethos>. Acesso em: 5 jul. 2015.

CHOPPIN, Alain. História dos Livros e das edições didáticas: sobre o estudo da arte. Rev. Educação \& Pesquisa. São Paulo, v. 30, n. 3, p. 549-566. set/dez. 2004. Disponível em: $<\mathrm{http} / / \mathrm{www}$. scielo.br/pdf/ep/v30n3/a12v30n3.pdf $>$. Acesso em: 3 fev. 2016.

FELDMAN, S.A. Como tratar dos judeus no ensino de Idade Média? Arquivo Maaravi: Revista Digital de Estudos Judaicos da UFMG. Belo Horizonte, v.6, n.11, out. 2012. ISSN: 1982-3053. Disponível em: <file://C:/Users/User/Downloads/3077-8712-1-PB\%20(5).pdf.>. Acesso em: 23 mar. 2016.

- Tolerância e marginalidade: os judeus na legislação castelhana do século XIII e início do séc. XIV. In: XX Encontro Regional de História: História e Liberdade, 9, 2010, Franca. Anais. Franca: ANPUH/SP - UNESP, 2010. Disponível em: $\leq$ http://www.anpuhsp.org.br/sp/downloads/CD\%20XX\%20Encontro/ PDF/Autores\%20e\%20Artigos/Sergio\%20Alberto\%20Feldman.pdf.> Acesso em: 5 ago. 2015.

FONSECA, S. G. A História na Educação Básica: conteúdos, abordagens e metodologias. I Seminário Nacional do Currículo em Movimento: Perspectivas Atuais, Anais. 11, 2010, Belo Horizonte. Disponível em: <http://portal.mec.gov.br/docman/dezembro-2010pdf/7168-3-4-historia-educacao-basica-selva/file>. Acesso em: 9 mai. 2015.

FRANCO JÚNIOR, H. Raízes medievais do Brasil. Rev. USP, São Paulo, n.78, p. 80-104, jun/ago. 2008.

FREYRE, G. Casa grande e senzala: formação da família brasileira sob o regime da economia patriarcal. 48. ed. Recife: Global Editora, 2003.

GODOY, A. S. Introdução à pesquisa qualitativa e suas possibilidades. Rev. de Administração de Empresas, São Paulo,v. 35, n. 2, p.57-63, mar/abr. 1995. Disponível em: http://www.scielo.br/pdf/rae/v35n2/a08v35n2.pdf. Acesso em: 10 out. 2015.

LE GOFF, J. Uma longa Idade Média. 3. ed. Rio de Janeiro: Civilização Brasileira, 2008. 
LIMA, M. P. Representações da Península Ibérica nos livros didáticos: os (des)compassos entre a escola e a academia. Rev. História Comparada, Rio de Janeiro, v. 6, n.1, p. 165-196, jul. 2012. Disponível

em: $<$ http://www.ppghc.historia.ufrj.br/images/publicacoes/2012/numero1/volume-6-n-1-edicao-completa.pdf $>$. Acesso em: 17 fev. 2015.

MACEDO, J. R. Repensando o ensino da Idade Média no ensino de História. In: KARNAL, Leandro. História na sala de aula: conceitos, práticas e propostas. São Paulo: Contexto, 2007.

OLIVEIRA, N. A. S de. Os estudos da Idade Média em livros didáticos e suas implicações no Ensino de História. Cadernos do Aplicação (UFRGS), Porto Alegre, v. 23, n.1, p. 101-123, 2010.

PEDRERO-SANCHES, M. G. A Península Ibérica entre o Oriente e $o$ Ocidente: cristãos, muçulmanos e judeus. 2. ed. São Paulo: Atual, 2005.

RUCQUOI, A. História Medieval da Península Ibérica. Lisboa: Editorial Estampa, Lda., 1995.

SAID, E. W. Orientalismo: o Oriente como invenção do Ocidente. Tradução Tomás Rosa Bueno. São Paulo: Companhia das Letras, 1990.

SILVA, A. C. L. F. A Península ibérica medieval no Programa de Estudos Medievais de UFRJ. Rev. Diálogos Mediterrânicos. Curitiba, n. 2, maio. 2012. Disponível em: $<$ http://www.dialogosmediterranicos.com.br/index.php/RevistaDM/ar ticle/view/24/68> _ Acesso 3 mar. 2015.

SILVEIRA, A. D. Europeização e/ou Africanização da Espanha Medieval: Diversidade e unidade cultural europeia em debate. História, Franca, v. 28, n. 2. 2009. Disponível em: $<$ http://www.scielo.br/pdf/his/v28n2/22.pdf $>$. Acesso em 27 ago. 2016.

. Fronteiras da tolerância e identidades na Castela de Afonso X. In: FERNANDES, F. R. Identidade e fronteiras no medievo ibérico. Curitiba: Juruá Editora, 2013.

RECEBIDO EM 22/02/2018 APROVADO EM 12/09/2018 